\title{
Processo de trabalho e produção do cuidado em Centro de Atenção Psicossocial: Um
}

\section{relato de caso}

\author{
Process of work and production of care in caps: A case report \\ Proceso de trabajo y producción de atención en caps: Reporte de caso
}

Recebido: 22/06/2021 | Revisado: 28/06/2021 | Aceito: 01/07/2021 | Publicado: 14/07/2021

\author{
Diogo de Oliveira Boccardi \\ ORCID: https://orcid.org/0000-0003-4284-4634 \\ Universidade Federal de Santa Catarina, Brasil \\ E-mail: diboccardi@gmail.com \\ Jeferson Rodrigues \\ ORCID: https://orcid.org/0000-0002-8612-9088 \\ Universidade Federal de Santa Catarina, Brasil \\ E-mail: jeferson.rodrigues@ufsc.br
}

\begin{abstract}
Resumo
Este artigo consiste em um relato de experiência de organização do processo de trabalho em um Centro de Atenção Psicossocial da região Sul do Brasil, analisado utilizando a metodologia do Fluxograma Descritor. O objetivo principal é compartilhar publicamente as estratégias construídas para a organização do serviço e a produção do cuidado em saúde mental. Observou-se grande sistematização do processo de trabalho, que prioriza o atendimento às demandas espontâneas de pacientes novos ou daqueles que já têm Projetos Terapêuticos Singulares no serviço, incluindo sobretudo as situações de crise e urgência em saúde mental.
\end{abstract}

Palavras-chave: Serviços de saúde mental; Serviços de saúde da criança; Psicologia da criança; Ensino superior.

\begin{abstract}
This article is an account of experience of organization of the work process in a Psychosocial Care Center of the Southern region of Brazil, analyzed using the methodology of the Flowchart Descriptor. The main objective is to publicly share the strategies built for the organization of the service and the production of mental health care. It was observed a great systematization of the work process, which prioritizes the spontaneous demands of new patients or those who already have Singular Therapeutic Projects in the service, including especially situations of crisis and urgency in mental health.
\end{abstract}

Keywords: Mental health services; Child health services; Psychology, child; Education, higher.

\section{Resumen}

Este artículo consiste en un informe sobre la experiencia de organizar el proceso de trabajo en un Centro de Atención Psicosocial en el sur de Brasil, analizada mediante la metodología Descriptor Flowchart. El objetivo principal es compartir públicamente las estrategias construidas para la organización del servicio y la producción de atención en salud mental. Hubo una gran sistematización del proceso de trabajo, que prioriza atender las demandas espontáneas de nuevos pacientes o de aquellos que ya cuentan con Proyectos Terapéuticos Únicos en el servicio, incluyendo sobre todo situaciones de crisis y urgencia en salud mental.

Palabras clave: Servicios de salud mental; Servicios de salud del niño; Psicología infantil; Educación superior.

\section{Introdução}

Passadas quase duas décadas da promulgação da Lei 10.216 de 06 de abril de 2001 (Brasil, 2001), chamada de Lei da Reforma Psiquiátrica Brasileira, e com portarias que regulamentam a atuação dos Centros de Atenção Psicossocial (CAPS), ainda é premente refletir: como deve funcionar um CAPS? Considero demasiadamente problemática a expressão "deve" no que tange a este questionamento. Como espaços de invenção de um modo de relação que privilegia as singularidades e que leva em conta os meandros do contexto em que se insere, cada CAPS "deve" poder pensar sobre sua função e seu processo de trabalho, respeitando as diretrizes e princípios do SUS, as características demográficas, culturais e epidemiológicas da região e o perfil da equipe e da rede intersetorial. Sobretudo, “deve" envolver os usuários e a comunidade no desenvolvimento de estratégias de cuidado e emancipação. Por isso resulta difícil padronizar o processo de trabalho de diferentes serviços: 
Mediante as transformações práticas produzidas a partir da expansão dos CAPS, entendemos que elas têm potencial para impactar as realidades locais, configurando-se como um dos equipamentos centrais na implantação do Sistema Local de Saúde Mental. Por outro lado, as diversidades contextuais não permitem que esse processo ocorra de forma linear e homogênea, sendo condicionada a sua implementação por fatores técnicos, políticos, econômicos, culturais, entre outros (Kantorski, Wetzel, Olschowsky, Jardim, Bielemann \& Schneider, 2019).

Não há um modelo pronto e definitivo de como deve funcionar um CAPS mas, decorridos tantos anos de atuação, há no Brasil uma profusão de experiências criativas e rigorosas de definição do processo de trabalho nos serviços. Tais experiências, contudo, nem sempre são publicizadas e debatidas, o que dificulta o avanço da Reforma Psiquiátrica. Como trabalhadores de um CAPS e pesquisadores no campo da Saúde Mental Coletiva, propomos neste texto compartilhar como nossa equipe vem dirigindo a Unidade e pensando a articulação com as Redes de Atenção. Não se trata aqui de sugerir que outros serviços adotem o mesmo modelo, mas de apresentar a singularidade de nosso trabalho para que as diferenças se evidenciem e possam mover a reflexão a nossa e a de outras equipes em diferentes contextos.

O serviço analisado encontra-se na capital de um Estado da região sul do país e é o único CAPS geral tipo II, referência para todas as Unidades Básicas de Saúde. O município tem mais de 470 mil habitantes, segundo dados do Instituto Brasileiro de Geografia e Estatística (2020). Estas e outras características, como apresentado mais abaixo, permitem pensar neste como um caso a ser analisado em seus potenciais e dificuldades, exemplo possível na variedade de experiências em curso no Brasil.

\section{Metodologia}

Trata-se de um estudo descritivo, do tipo relato de experiência e correlacionado com a revisão bibliográfica do tipo narrativa. Segundo Minayo (2014) o estudo descritivo contextualiza a realidade do objeto empírico para viabilizar seu aprofundamento e a descrição das vivências permite produzir um novo conhecimento da realidade investigada. Para Santos (2008), o relato de experiência sistematiza uma vivência a partir de fatos experienciados com a fundamentação teórica e produz um saber sobre o objeto estudado. Os dados apresentados a partir da descrição do relato de experiência provêm de discussões com a equipe técnica do serviço e dos documentos produzidos no município, incluindo a legislação vigente, os protocolos e fluxogramas adotados.

Ademais foi utilizado a revisão bibliográfica do tipo narrativa que, para Prado, Morillas-Bulnes e Moran-Pena (2013), contextualiza as produções de um determinado objeto ou tema, onde o pesquisador interpreta e analisa esses estudos, o método e a seleção das produções científicas e técnicas são planejadas e organizadas conseguinte ao interesse do pesquisador e ao acesso na íntegra dessas mesmas produções. Essa revisão bibliográfica do tipo narrativa foi realizada no portal CAPES, buscou-se estudos sobre a história da saúde mental no país, no estado e no município. Também foram utilizados documentos técnicos específicos do município de Florianópolis. Para a sistematização desse estudo, foi utilizado o "Fluxograma Descritor" como ferramenta de análise do processo de trabalho (Franco \& Merhy, 2013).

\section{Comentários Sobre a História da Atenção Psicossocial e a Situação da Raps no Estado e no Município Analisados}

O CAPS que ora analisamos foi o primeiro Centro de Atenção Psicossocial gerido pelo município, inaugurado em 1996 mas já em funcionamento desde o final de 1995 - ou seja, antes mesmo da promulgação da Lei 10.216 de 06 de abril de 2001 (Brasil, 2001) da Reforma Psiquiátrica, e Portaria GM no 336 (Brasil, 2002). Sua história remete à pré-história da atenção psicossocial no país. Como em tantos outros lugares, os hospitais-colônias foram dominantes, com seu modelo asilar, suas pretensões moralizantes e, sobretudo, os abusos, os maus-tratos, as mortes, o descaso e o abandono. O processo histórico e político que culminou com a abertura deste CAPS apresentou progressos e revezes comuns a outros serviços e outros municípios, 
mas também algumas particularidades.

Com efeito, as discussões que precederam à chamada Reforma Psiquiátrica Brasileira tiveram diferentes facetas em Santa Catarina. Antes da criação dos CAPS/NAPS pelo governo federal, observou-se uma mudança de mentalidade em termos técnicos e políticos que incorreu na disputa de ideias e de espaços de atuação em saúde mental. Um exemplo disso foi o movimento realizado pelo governo estadual na década de 1970, que pretendia construir novos hospícios. Diante da pressão de grupos diversos - e não necessariamente coesos - optou-se por suspender a inauguração do Hospital Psiquiátrico estadual na região do extremo oeste catarinense. Concomitantemente, ocorreram iniciativas de desospitalização de pacientes internados por vários anos no Hospital Colônia Santana, atualmente nomeado como Instituto de Psiquiatria de Santa Catarina (Ribas, Borenstein \& Padilha, 2007).

Com a criação de Núcleos/Centros de Atenção Psicossocial (NAPS/CAPS) através da Portaria/SNAS nº 224, de 29 de janeiro de 1992 (Brasil, 1994), vimos iniciativas pioneiras de oferta de atendimento em saúde mental alternativas ao manicômio ganharem respaldo institucional. Estes serviços foram instituídos como unidades de saúde regionalizadas, cuja função seria oferecer cuidados intermediários entre o regime ambulatorial e a internação hospitalar. Neste contexto foi criado, em 1989, um CAPS em Florianópolis gerido pela Secretaria de Estado da Saúde (ibidem), por iniciativa de profissionais anteriormente lotados no Instituto de Psiquiatria (IPq). Num momento em que havia apenas um único profissional de saúde mental contratado no município de Florianópolis, este serviço abriu as portas para o atendimento em liberdade e junto às famílias dos sujeitos que, até então, tinham como único destino o aprisionamento perpétuo nos manicômios.

Em 1995 iniciaram-se as atividades de um novo CAPS, sob gestão própria do município. Sua atuação, afinada à lógica da Reforma Psiquiátrica e dos movimentos sociais de luta antimanicomial, foi reconhecida e repercutiu no cenário nacional (Lancetti, 2007). Também relevante é a existência da Associação de Usuários do CAPS, ainda em atividade (Rodrigues, Brognoli \& Spricigo, 2006). Passados mais de 20 anos de trabalho, este CAPS continua sendo o único de tipo II para atendimento geral à população adulta de um município de mais de 470 mil habitantes, segundo estimativa de 2019 do Instituto Brasileiro de Geografia e Estatística (2020). Conforme avançou a legislação brasileira, com o advento da Lei 10.216 de 06 de abril de 2001 (Brasil, 2001), e da Portaria GM nº 336 (Brasil, 2002), o CAPS assumiu o papel de articulador e de centro de referência para o cuidado em saúde mental. Com uma importante inflexão das políticas, operada pela Portaria 3.088 de 2011 (Brasil, 2011), que instituiu a RAPS (Rede de Atenção Psicossocial), a equipe do serviço passou a delinear suas ações segundo a lógica da rede, o que significa conceber a centralidade do cuidado no sujeito e nas relações que trava no seu entorno, e não mais no próprio CAPS. Disso decorre que o CAPS deixa de ser o principal responsável pela articulação do atendimento, compartilhando com a Atenção Primária em Saúde tal tarefa - processo sempre em construção.

Neste momento, a Rede de Atenção Psicossocial do município conta com os seguintes dispositivos: um CAPS tipo II (analisado neste trabalho), dois CAPSad, um CAPSi, uma comunidade Terapêutica conveniada, com 30 vagas, Equipes de Saúde Mental no NASF (psicólogos e psiquiatras de referência para cada Unidade Básica de Saúde), um Centro de Convivência e Cultura conveniado (uma ONG com quase trinta anos de atuação em saúde mental e direitos humanos), Equipes de SAMU e duas Unidades de Pronto Atendimento, e uma equipe de Consultório na Rua vinculada à Atenção Primária em Saúde.

Importante notar a ausência de Serviços Residenciais Terapêuticos, Unidades de Acolhimento, CAPS tipo III e, principalmente, leitos de atenção integral em hospital geral. Deste cenário decorre uma séria precarização do atendimento às crises e urgências em saúde mental, que têm sido atendidas pelos CAPS (com limitações, em função do horário de funcionamento das unidades restrito ao período diurno). A equipe do CAPS II tem desempenhado importante papel de fortalecimento do atendimento às situações de crise pelo cuidado em liberdade, prescindindo do encaminhamento dos sujeitos ao hospital psiquiátrico e investindo sobretudo no manejo verbal das formações psicóticas, neuroses graves e dos comportamentos suicidas. 


\section{O Processo de Trabalho do CAPS}

O planejamento das ações do trabalho no CAPS analisado é realizado pela equipe de forma participativa, segundo as características da RAPS na região. Salienta-se conforme Soares, Pereira \& Lima (2020) que essa participação dos trabalhadores nos processos de gestão á uma competência primordial para a efetividade dos CAPS. Destarte, semanalmente é realizada a reunião técnica, em que se discute o processo de trabalho, as prioridades do serviço e a distribuição das responsabilidades entre os profissionais. Nas assembleias de usuários e profissionais se busca incluir os pacientes e familiares no processo decisório empreitada sempre em construção e com muitas contradições. O financiamento do serviço é majoritariamente de recursos próprios do município, contando apenas com o repasse do Ministério da Saúde, no valor de $\mathrm{R} \$ 33.086,25$ (trinta e três mil e oitenta e seis reais e vinte e cinco centavos) mensais.

Atualmente a equipe do CAPS II conta com sete profissionais de nível superior e cinco de nível médio (conforme mostra a Tabela 1) admitidos por meio de concurso público. Além disso, trabalham conosco diariamente uma auxiliar de serviços gerais e um profissional de vigilância, em regime de terceirização.

Tabela 1 - Equipe do CAPS II, por categoria profissional.

\begin{tabular}{lcc}
\hline Categoria profissional & Número de profissionais & Carga horária* \\
\hline Médico psiquiatra & 2 & $60 \mathrm{~h} / \mathrm{semana}$ \\
Psicólogo & 3 & $90 \mathrm{~h} / \mathrm{semana}$ \\
Enfermeiro & 1 & $40 \mathrm{~h} / \mathrm{semana}$ \\
Técnico de Enfermagem & 2 & $80 \mathrm{~h} / \mathrm{semana}$ \\
Técnico administrativo & 3 & $90 \mathrm{~h} / \mathrm{semana}$ \\
Assistente social & 1 & $30 \mathrm{~h} / \mathrm{semana}$ \\
\hline \multirow{2}{*}{ Carga horária total (soma das horas trabalhadas por cada profissional desta } \\
categoria, por semana) \\
Fonte: Autores (2021).
\end{tabular}

Com apenas nove profissionais vinculados às atividades-fim, a equipe é responsável pelas ações de cuidado, reabilitação psicossocial e, em conjunto com os NASFs, matriciamento das equipes da Estratégia de Saúde da família para toda a população. Com cerca de 300 usuários em acompanhamento regular em 2019 temos uma relação usuário-trabalhador de 30 para 1, um número bastante elevado. Para efeitos de comparação: segundo pesquisa realizada em 2006 nos CAPS do município de Campinas (SP), a relação usuário-trabalhador era de, em média, 6,3/1. O cálculo leva em conta profissionais de nível superior e médio que atuam em áreas-fim, excetuando aqueles que trabalham apenas em atividades administrativas como limpeza e vigilância (Figueiredo, Santos \& Weller, 2008). Também temos buscado a parceria das Universidades, sobretudo através de estágios de graduação e residência. Entre as atividades desenvolvidas, destacam-se as seguintes: Avaliação em saúde mental por demanda espontânea; Atendimento individual em cada especialidade /categoria profissional; Oficinas terapêuticas, de socialização e de reabilitação psicossocial; Psicoterapia individual e em grupo; Atendimento familiar, Grupo de Famílias e orientação à rede social de apoio; Elaboração e gerenciamento de Projetos Terapêuticos Singulares; Reuniões de Equipe; Reuniões intersetoriais, discussões de caso e articulação de rede; Supervisão de estágios de graduação (Psicologia, Enfermagem e Serviço Social), de residência médica (Medicina de Família e Comunidade) e residência multiprofissional (Saúde da Família); Oferta de palestras e cursos de capacitação para rede intersetorial; Resposta a demandas judiciais; Atestados e encaminhamento para obtenção de Passe Livre Municipal; Encaminhamento para atendimento em outros pontos de atenção, conforme necessidades e direitos dos usuários (incluindo saúde, educação, cultura, justiça, trabalho, assistência social e outros); Assembleia de usuários e profissionais; Supervisão de administração de medicação para pacientes sem condições de gerir seu cuidado; Intensificação de cuidados para pacientes graves; Espaço de convivência para internos do Hospital de Custódia e Tratamento Psiquiátrico (HCTP); Fornecimento de alimentação (Brasil, 2002); Visitas Domiciliares e Institucionais; Elaboração de atestados, relatórios e outros documentos, conforme solicitação do paciente ou do Judiciário; Apoio à Associação AlegreMente (associação de usuários do 
CAPS e familiares).

\section{Acesso ao CAPS e Início do Acompanhamento}

Sendo porta de entrada da rede, o serviço mantém um profissional sempre disponível para receber as pessoas que forem encaminhadas ou que demandem espontaneamente uma avaliação em saúde mental. Elas são acolhidas a qualquer tempo em que a Unidade está aberta, sem necessidade de agendamento e sem restrição de vagas. Todos os profissionais da equipe, independente da formação, estão capacitados para realizar a avaliação inicial e o primeiro manejo verbal das situações de sofrimento, bem como dar orientações e deliberar sobre o seguimento e encaminhamentos. O Projeto Terapêutico Singular é construído após período inicial de avaliação pela Equipe de Referência. Conforme Figura 1, foi elaborado um fluxograma descritor para melhor analisar o acesso inicial dos usuários ao serviço.

Figura 1 - Fluxograma de acesso ao CAPS por demanda espontânea ou encaminhamento.

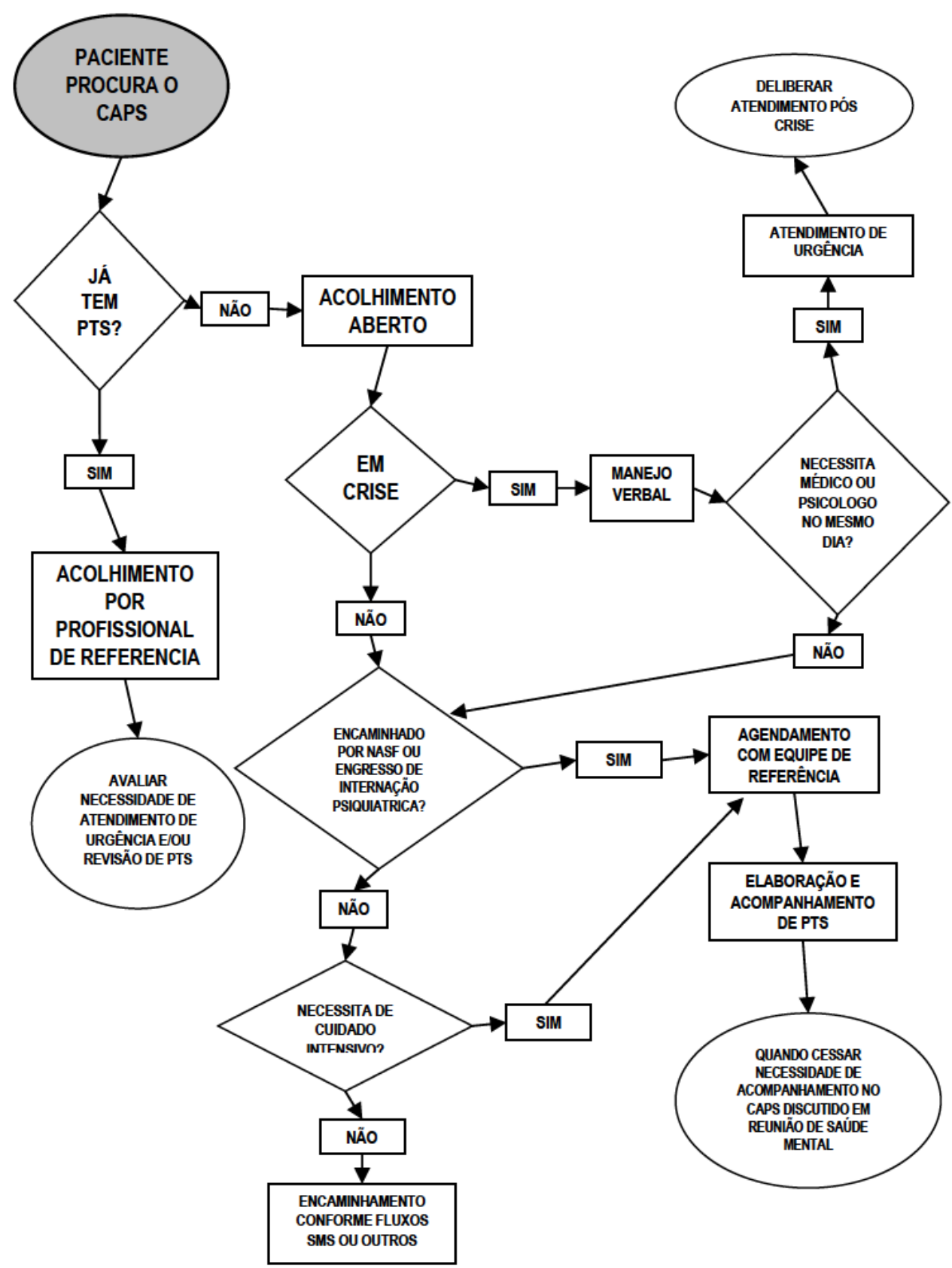

Fonte: Autores (2021). 
É possível observar no fluxograma apresentado na Figura 1 que estabelecemos quatro critérios para inclusão de pacientes novos no CAPS: 1) quadro de crise e urgência em saúde mental, no momento da avaliação; 2) ser egresso de internação psiquiátrica; 3) ter sido avaliado e encaminhado por profissional da equipe NASF; e 4) necessitar de cuidado intensivo. Qualquer desses critérios já aduz ao encaminhamento para atendimentos posteriores com a equipe de referência no CAPS. Visando garantir o cuidado integral em saúde à população e organizar a articulação da RAPS no município, pactuou-se que os usuários que procurem o CAPS mas que não tenham sido avaliados pela equipe NASF sejam direcionados para as Unidades Básicas de Saúde (ou a outro ponto da rede intersetorial, conforme a necessidade) após avaliação e orientação, para atendimento mais próximo ao seu domicílio.

Quando usuários que já são acompanhados no CAPS e já têm Projeto Terapêutico Singular procuram atendimento espontaneamente, serão acolhidos por um profissional de sua Equipe de Referência, que já o conhece e tem mais condições de reavaliar suas necessidades e dar o seguimento necessário ao cuidado.

\section{Equipes de Referência por Distrito Sanitário}

Com vistas à regionalização da Atenção Primária, o município de Florianópolis está dividido em quatro Distritos Sanitários de Saúde. Nessa lógica, a equipe do CAPS também tem se organizado por Equipes de Referência (ER) para cada Distrito, além de duas ER especiais: uma para a população em situação de rua e outra para apoiar o processo de desinstitucionalização de internos do Hospital de Custódia e Tratamento Psiquiátrico (HCTP). Alguns autores, como Amancio (2012) e Oliveira (2010), têm destacado a importância de que o técnico de referência seja eleito em função da afinidade do usuário, e não de forma burocratizada. Compreendendo a relevância disso, mas também querendo privilegiar a articulação do atendimento em rede, adotamos a distribuição das equipes pelo território e, dentro da mesma equipe, o usuário pode definir espontaneamente a quem recorrer com mais prontidão. A implantação das ERs se deu em função da necessidade de que cada usuário do serviço estabelecesse vínculos com quem o acompanha e de que a equipe tivesse conhecimento sobre a história, a família, as vulnerabilidades e os recursos do território dos pacientes.

Estando no território, o HCTP mantém convênio com o município para que seus internos possam usar o CAPS como espaço de convivência. Neste sentido, dispomos de dez vagas para usuários que estejam em processo de avaliação da cessação de periculosidade. Eles passam o dia no CAPS, seja em atividades grupais como oficinas, seja apenas permanecendo no ambiente da maneira que lhes convier. Por determinação judicial, os usuários não estão autorizados a deixar as dependências do CAPS, mas pactuamos que não serão acompanhados por agente penitenciário. Mais recentemente, alguns dos internos acompanhados por nós têm recebido alta/cessação de periculosidade, abrindo a possibilidade de retornar ao convívio em liberdade no território. Em função do longo período de aprisionamento, no entanto, este se revela um difícil processo, que exige o acompanhamento próximo e constante dos profissionais visando encontrar, organizar e mobiliar uma casa, manejar as relações e estigmas na vizinhança, garantir a continuidade do cuidado em saúde mental e fortalecer vínculos socioafetivos. Por este motivo, alguns dos trabalhadores do serviço compuseram uma equipe de referência específica para apoiar os egressos. Isso porque a equipe multidisciplinar como dispositivo em saúde mental nos CAPS possibilitam a clínica ampliada na singularidade de cada caso (Portal, Santos, Guimarães, Barreiros, Pinto, Dias, Moraes \& Mendonça, 2021). Cada uma das equipes de referência é composta por um psicólogo, um psiquiatra, um assistente social e um profissional de enfermagem (enfermeiro ou técnico). O número reduzido de profissionais atualmente no serviço exige que cada trabalhador participe de mais de uma equipe de referência. Assim, definimos que o acompanhamento longitudinal por especialidade (sobretudo os atendimentos psiquiátricos e as psicoterapias individuais e grupais) serão realizadas pelo profissional de referência da região em que o usuário reside.

Aos profissionais que compõem a ER cabe construir e reavaliar o Projeto Terapêutico Singular, prestar atendimento clínico e discutir os casos, articular o cuidado compartilhado com outros pontos de atenção, elaborar documentos, deliberar 
encaminhamentos e acolher os usuários. Para que os usuários possam acessar a ER, os profissionais reservam um horário por semana para a reunião com todos aqueles que têm demandas por documentos ou que precisam reavaliar seus Projetos Terapêuticos, espaço que chamamos de Grupo Multiprofissional do Distrito.

Uma das atividades principais deste grupo é realizar a avaliação multiprofissional de novos pacientes que ingressam para acompanhamento no serviço, iniciando a construção do Projeto Terapêutico Singular e agendando as consultas que se fizerem necessárias. As consultas de retorno (principalmente de psiquiatria e psicologia) são marcadas pelo profissional e pelo paciente durante o atendimento individual, garantindo que o usuário já saia da consulta com seu agendamento para a próxima. A qualquer tempo, o usuário ou sua família podem procurar os profissionais de referência e solicitar atendimento. A solicitação é verificada em sua urgência e o usuário é direcionado para o profissional que melhor comtemple sua necessidade.

Ainda que nem todas as atividades sejam distritalizadas (a participação em oficinas de socialização e reabilitação e os grupos de intensificação de cuidados são abertos a usuários independente da região em que moram), a indicação e o acompanhamento da participação são agenciados pela ER do sujeito.

\section{Elaboração dos Projetos Terapêuticos Singulares}

Tendo sido identificada a necessidade de atendimento sistemático no CAPS, o usuário é referenciado à equipe que discutirá a elaboração de seu Projeto Terapêutico Singular (PTS). Para Oliveira, Fonseca, Carmos, Braga, Lima, Mamed, Vale, Magalhães, Baptista \& Lopes (2021) o PTS é uma ferramenta organizadora do cuidado que possibilita o protagonismo e autonomia do cuidado entre a equipe de referência e o usuário. Tal processo se dá em função das vulnerabilidades identificadas em cada contexto intersubjetivo. Mais do que os diagnósticos psiquiátricos, a equipe lança mão das grandes categorias compreensivas (neurose, psicose e perversão) para indicar cada tipo de atividade ou atendimento. Isso não significa que haja uma uniformidade teórica entre os profissionais (que têm formação em diferentes abordagens clínicas). De todo modo, consensuou-se a importância de acompanhamento psicológico (individual ou em grupo) para quadros neuróticos. Também questionamos a inclusão indiscriminada de usuários em oficinas terapêuticas "de socialização". O questionamento vai no sentido de respeitar os modos de resistência dos sujeitos (mormente tratados como "sintomas") às demandas dirigidas a eles, que muitas vezes se constituem em demandas por socialização (Müller-Granzotto \& Müller-Granzotto 2012). Assim, entendemos que a construção de um projeto terapêutico deve poder ser uma defesa do direito de cidadania dos modos de vínculo singulares, mesmo quando eles possam representar "transtornos". Vemos aí a terapêutica compreendida como crítica sociall1, no espírito da Reforma Psiquiátrica de caráter antimanicomial: garantia das diferenças, da alteridade.

O respeito às singularidades não significa a inoperância das propostas práticas. As terapêuticas utilizadas partem da noção de clínica como estabelecimento de relações diferenciadas daquelas em que os "pacientes" estão inseridos. Não uma norma (como se um outro único modo de se relacionar pudesse substituir a exclusão do modelo manicomial), mas uma multiplicidade de desvios e formas acolhimento. E não à toa lanço mão da palavra "acolhimento", haja vista este não poder ser resumido a um momento de atendimento ou à triagem do serviço, mas sim inscrito como lógica da atenção e do cuidado (Brasil, 2004). Sabemos o que, grosso modo, se pede de um serviço de "saúde mental". Nas palavras de Soler (2012, p. 201) "Vasto programa: fazer o anoréxico comer, a muda falar, o deprimido sorrir, o estressado ficar tranquilo, o agitado, calmo, e tudo para ele está bom. É patente: é a hora dos psicotrópicos. E... do psi, talvez menos pior, mas que 'leva ao pior". Se um CAPS fica alienado a corresponder a este programa, pouco ou nada poderá fazer para promover a dignidade e a ampliação da contratualidade dos sujeitos que acompanha.

A proposição de um Projeto Terapêutico é a ocasião do estabelecimento de vínculos de cuidado e de ações de saúde. Sendo definido por Merhy como: 
No processo de trabalho em saúde há um encontro do agente produtor, com suas ferramentas (conhecimentos, equipamentos, tecnologias de um modo geral), com o agente consumidor tornando-o, parcialmente, objeto da ação daquele produtor, mas sem que com isso deixe de ser também um agente que, em ato, coloca suas intencionalidades, conhecimentos e representações, expressos como um modo de sentir e elaborar necessidades de saúde (Merhy, 1997, p. 175).

Sabemos que as relações de cuidado podem se dar de maneira burocratizada, demasiadamente prescritiva e hierárquica, através da mera oferta de "procedimentos" e "intervenções" (Franco, 2013). Para que não seja assim, apostamos nas tecnologias leve-duras e leves. Tomamos aqui a analogia feita por Merhy (1997, p. 176) para descrever as tecnologias de produção do cuidado:

Acredito que o trabalhador, para atuar, utiliza três tipos de valises: uma que está vinculada a sua mão e na qual cabe, por exemplo, um estetoscópio, bem como uma caneta, papeis, entre vários outros tipos que expressam uma caixa de ferramentas tecnológicas formada por 'tecnologias duras'; outra que está na sua cabeça e na qual cabem saberes bem estruturados como a clínica ou a epidemiologia ou a pedagogia, que expressam uma caixa formada por 'tecnologias leve-duras'; e, finalmente, uma outra que está presente no espaço relacional trabalhador-usuário e que contem 'tecnologias leves' implicadas com a produção das relações entre dois sujeitos, que só têm existência em ato. (Merhy,1997, p. 176).

Sem abrir mão dos conhecimentos produzidos pelos saberes técnico-científicos, "originados seja da clínica, epidemiologia, psicanálise, sociologia da saúde (...) [ou] ainda os saberes que são acumulados através da experiência de trabalho e experiência de vida" Franco (2013, p.320), entre outros, trata-se realmente de construir um espaço intersubjetivo que favoreça a emergência de um campo clínico (ampliado) capaz de provocar desvios (parênklises) no modo como a cidade (e a pessoa) vê a si própria (Müller-Granzotto \& Müller-Granzotto 2012), sem incorrer em dogmas, metas e finalidades estabelecidas a priori. "Por isso, esses processos são regidos por tecnologias leves que permitam produzir relações, expressando como seus produtos, por exemplo, a construção ou não de acolhimentos, vínculos e responsabilizações, jogos transferenciais, entre outros." (Merhy 1997, p. 178).

Não é sem dificuldades, entretanto, que o fazemos. Na Figura 2 conta o fluxograma descritor, tentamos explicitar o processo de trabalho adotado no CAPS para construir e gerenciar os Projetos Terapêuticos. 
Figura 2 - Fluxograma de elaboração do PTS e atendimento por demanda espontânea.

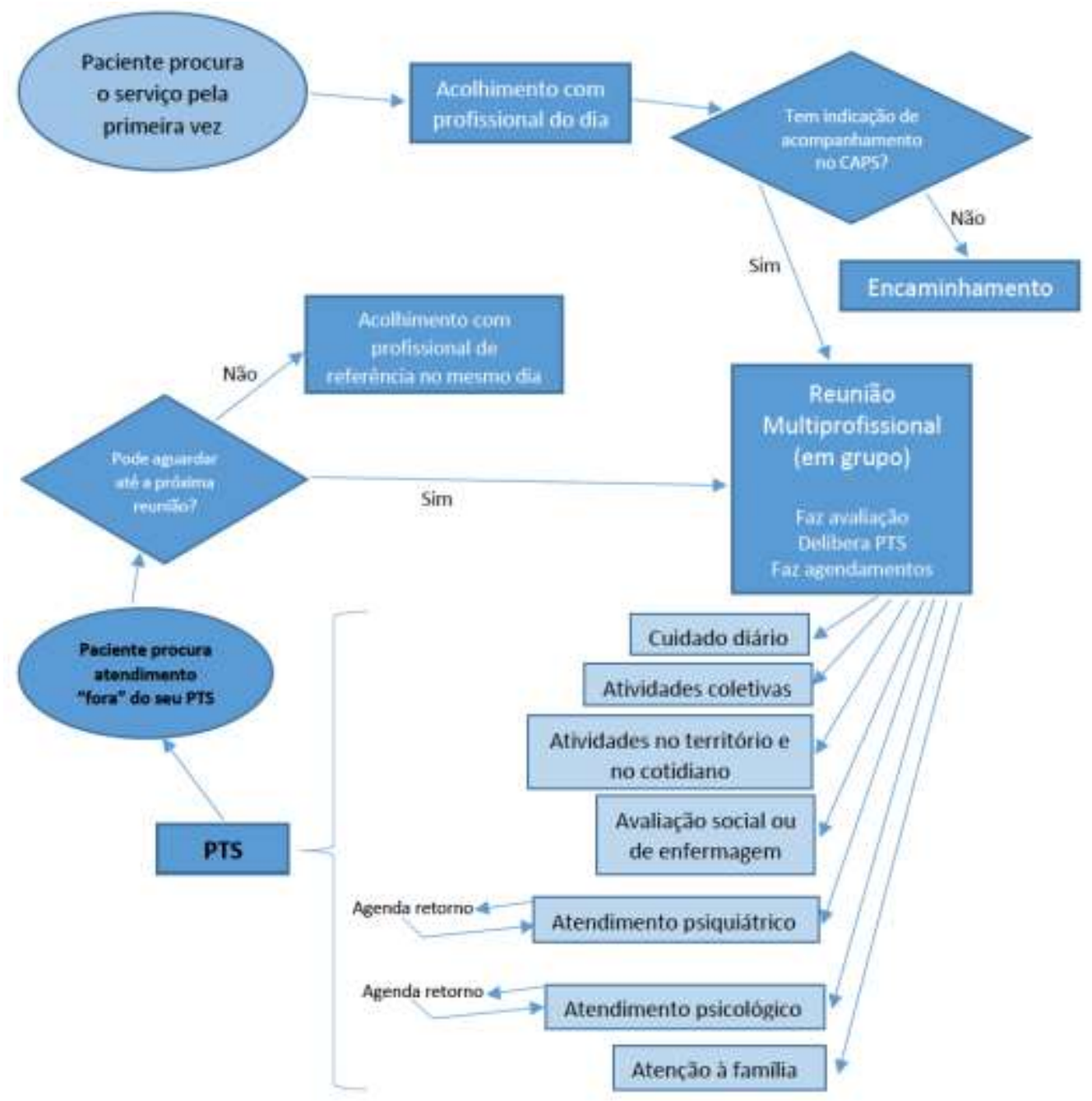

Fonte: Autores (2021).

Analisando o fluxograma, nota-se a tentativa de garantir que o acolhimento às demandas do usuário seja realizado pelos profissionais que compõem sua Equipe de Referência, conhecem sua biografia e suas formas de sofrimento/satisfação - o que inclui elaborar o PTS. A avaliação da ER vai determinar, levando em conta os desejos do usuário, quais as terapêuticas indicadas para cada momento e situação de vulnerabilidade. Após a pessoa ser acolhida pela primeira vez no serviço e tendo sido identificada a indicação de acompanhamento no CAPS (segundo os critérios apresentados acima, no fluxograma descrito na Figura 1), o usuário é direcionado à Reunião Multiprofissional da sua ER, um grupo com frequência semanal em que poderá expor suas necessidades, conhecer o funcionamento do serviço, interagir com outros usuários e discutir as ações que serão tomadas como seu projeto terapêutico. Este é um grupo aberto, coordenado por todos os profissionais da ER, que pode ser acessado espontaneamente. É entendido como um espaço de gerenciamento e reavaliação dos PTS. É também o momento em que os usuários podem solicitar reagendamento das consultas (caso não tenham conseguido comparecer a um atendimento agendado ou precisem de outra avaliação antes da próxima consulta psicológica ou psiquiátrica), documentos como atestados ou cópias de prontuário, ou orientações de qualquer natureza.

Os usuários também podem, a qualquer tempo, solicitar atendimento de algum profissional de referência e, caso sua demanda não possa aguardar até o dia da próxima reunião, ele é acolhido no mesmo dia. Sendo possível "resolver" o pedido apresentado, o profissional de referência toma as medidas necessárias (incluindo solicitar interconsultas com profissionais de outras especialidades, conforme o caso). Caso a solicitação exija revisão do PTS (por agudização ou mudança no quadro, ou 
mesmo por uma melhora significativa), o usuário é novamente encaminhado para a reunião multiprofissional. Tais medidas têm por função evitar a criação de barreiras de acesso ao serviço, ao mesmo tempo em que permitem à equipe organizar seus horários e seu processo de trabalho.

Importante notar que as solicitações dos usuários não devem necessariamente ser "atendidas" de pronto, mas antes decupadas, elaboradas por eles mesmos com o apoio da equipe. Nem sempre a queixa sobre a ineficácia de certo esquema medicamentoso, em função de insônia ou do acirramento de delírios, por exemplo, indica a necessidade de mudança nos fármacos para suprimir os "sintomas". Ao contrário, podem ser a ocasião para compreender os desencadeantes psicossociais do sofrimento, orientando, quem sabe, a mediação das relações familiares. Ou o pedido de novo atestado para afastamento laboral pode permitir rediscutir os projetos pessoais do sujeito, ampliando os horizontes de futuro. Sobre a importância da elaboração (clínica) dos pedidos dirigidos aos profissionais e o risco de se atuar em um regime potencialmente paternalista, compartilhamos da inquietação de Tenório (2007):

Como formulação provisória, diria que a transformação do paciente em "usuário", sujeito de "direitos", se pode ter efeitos terapêuticos importantes na psicose, traz problemas clínicos específicos para o campo da neurose, na forma de uma adesividade do sujeito à ideia de que o tratamento tem o dever de lhe restituir o bem estar - imperativo do qual os profissionais têm dificuldade de se distanciar a fim de poderem oferecer uma resposta efetivamente clínica (Tenório, 2007, p.17).

Disso não decorre, evidentemente, destituir a cidadania e a garantia de direitos daqueles que frequentam serviços de saúde mental. Antes, importa localizar quais identidades sociais promovem o cerceamento da autonomia de cada um e operar desvios promotores de emancipação.

A elaboração do PTS propriamente dito, ou seja, das ações de atenção à saúde, não obedece a critérios rígidos e previamente determinados. Por um lado, isto dificulta a decisão da equipe e dos usuários sobre que propostas seriam mais interessantes para cada caso, bem como a avaliação sobre os benefícios terapêuticos das ações. Por outro lado, preserva a singularidade dos projetos e a flexibilidade das condutas. A avaliação das vulnerabilidades pode apontar para a necessidade de cuidado intensivo, diário, no serviço, por tempo indeterminado. Isso não significa que o usuário estará o tempo todo "em atividades", mas, sobretudo, que usará o espaço do CAPS e o relacionamento com profissionais e usuários como continente para seu sofrimento.

As atividades coletivas oferecidas pelo serviço podem ou não ocorrer na própria Unidade. Como já mencionado, o convênio travado pelo município com uma Associação de Direitos Humanos e Saúde Mental tem proposto utilizar este dispositivo como Centro de Convivência. Assim, as oficinas terapêuticas e as iniciativas de reabilitação psicossocial (conforme descrito mais à frente) podem ser acessadas por todos os usuários, mediante discussão com a equipe de referência.

Não acreditamos, no entanto, que todas as "atividades" devem ser oferecidas e coordenadas por profissionais ligados à saúde mental. Ao contrário, compreendemos que é justamente a inserção do sujeito na vida cotidiana (que pode incluir a participação em associações de bairro, espaços culturais ou religiosos, de lazer ou de trabalho, segundo os desejos de cada pessoa) o que diferencia a clínica proposta pela Reforma Psiquiátrica numa lógica antimanicomial. A ER, aqui, deve operar como agenciadora do acesso à vida da cidade - acesso esse muitas vezes negado aos sujeitos em função das diferenças comportamentais que apresentam e da cultura de segregação dominante. Isso inclui também fazer articulações intersetoriais, especialmente, mas não só, com os serviços de Assistência Social. Sabendo da importância dos determinantes sociais no processo de adoecimento (Alves \& Rodrigues, 2010), o esforço aqui é de promover mudanças micro e macrossociais na mesma medida em que se dá atenção à saúde das pessoas.

Também conforme avaliação, os usuários são encaminhados para atendimentos com profissionais de enfermagem, serviço social, psicologia e psiquiatria. A frequência varia a cada caso: via de regra, mensal ou bimestral para o acompanhamento 
longitudinal de psiquiatria e semanal ou quinzenal para psicoterapia (individual ou em grupo). O agendamento do retorno às consultas é feito pelo próprio profissional no dia do atendimento, de forma que não seja preciso que o paciente busque o serviço novamente ou "enfrente fila" para conseguir nova consulta. Os atendimentos de serviço social e enfermagem são agendados por demanda (sem horários pré-definidos nas agendas). Estamos tratando aqui dos atendimentos por núcleo de conhecimento, mas cabe lembrar que outras atividades, como a coordenação de oficinas e o acompanhamento do PTS como um todo, também são feitas por todos os profissionais, independente da especialidade ou categoria profissional.

Um dos pontos mais sensíveis, segundo avaliamos em nosso cotidiano, é o acompanhamento às famílias dos "pacientes identificados". Sensível por ser difícil efetivar, num serviço muitas vezes instado a funcionar como ambulatório, com poucos profissionais e numa sociedade individualista que produziu discursos psicopatológicos igualmente individualizantes. Mas também sensível por mostrar grandes resultados e exigir delicadeza, cuidado e flexibilidade dos profissionais. Durante alguns anos, nossa equipe investiu em grupos de famílias, abertos, mas observamos apenas uma pequena participação e de poucos familiares, sem a presença do usuário, com resultados exíguos. Por isso, no último ano, temos priorizado o acompanhamento mais próximo de cada família, o que possibilitou maior inserção da família ampliada (nem sempre facilmente acessada), maior vínculo desta com a equipe e maior capacidade de mediação. Sobretudo, temos conseguido identificar quais são as demandas dirigidas aos pacientes e o que possa estar exigindo deles as respostas (neuróticas, psicóticas ou outras) que apresentam e que aduzem ao rótulo de "doente". Neste tipo de atendimento, realizamos abordagens de orientação, mas também de cuidado para com os membros da rede social de apoio dos usuários do CAPS, haja vista também apresentarem, recorrentemente, situações de sofrimento.

Quando cessa a necessidade de acompanhamento regular no CAPS, os usuários são referenciados à sua Unidade Básica de Saúde para seguir o acompanhamento. O encaminhamento é oficializado nas Reuniões Distritais de Saúde Mental, que ocorrem mensalmente, em que participam os assistentes sociais, psicólogos e psiquiatras do NASF daquela região, mais um representante de cada CAPS do município. Os profissionais do NASF ficam então com a incumbência de garantir a continuidade do cuidado integral do usuário pela equipe de Saúde da Família e, quando for o caso, atender eles mesmos o paciente. A equipe do CAPS toma o cuidado de registrar em prontuário, à guisa de matriciamento, sua avaliação final do caso, explicitando os motivos do encaminhamento para a Atenção Primária, a prescrição de medicamentos mais recente, bem como orientações e sugestões para o seguimento do tratamento, levando em conta articulações intersetoriais, manejo da família, dados biográficos que se considere relevantes e outros elementos que possam favorecer a reabilitação psicossocial.

Ainda sobre este tema, duas questões importantes devem ser ressaltadas: 1) caso o encaminhamento seja realizado logo após o acolhimento inicial no serviço, sem que o paciente seja inserido para acompanhamento no CAPS, cabe ao profissional que realiza a avaliação fazer o registro desta e também orientar matricialmente, com sugestões de seguimento, a equipe de Saúde da Família através do prontuário eletrônico. 2) Se o paciente necessitar, a qualquer tempo e por qualquer razão, retornar ao CAPS, poderá fazê-lo. Para tanto, os profissionais do NASF levarão o caso para discussão com o profissional de referência do CAPS na Reunião Distrital de Saúde Mental.

\section{Avaliação Inicial e Atendimento às Crises}

Ainda que a avaliação inicial de saúde das pessoas que procuram o CAPS varie em função da formação e categoria profissional de cada membro da equipe, alguns elementos foram consensuados ao longo dos anos. Nenhum "instrumento" (questionário, formulário, escala etc.) padronizado é utilizado e, quando qualquer dúvida se apresenta, o profissional pode recorrer aos colegas para solicitar interconsultas ou deliberar o seguimento. Abaixo, apresento brevemente os pontos considerados indispensáveis na avaliação inicial: Estado mental (humor e afetividade, pensamento, atividade psicomotora, orientação no tempo e no espaço, linguagem, memória, cognição, juízo crítico); Sentimentos (do usuário e do profissional); 
Presença ou ausência de formações psicóticas (alucinatórias, delirantes, identificatórias ou de isolamento); Presença ou ausência de alterações de sono e apetite; Rede social de apoio; Histórico de tratamentos em saúde mental (especialmente internações psiquiátricas prévias); Ideação suicida atual ou pregressa, com estratificação de risco; Ideação auto ou heteroagressiva; Uso de substâncias psicoativas lícitas ou ilícitas, incluindo psicofármacos prescritos ou não por médico; Escolarização, condições de habitação/moradia, trabalho e renda

Além destes elementos, o profissional deve acolher a história de vida e os sofrimentos apresentados, realizar manejo verbal das demandas e prestar as orientações que se fizerem necessárias.

Assumindo como função crucial dos CAPS o manejo das situações de crise e urgência em saúde mental, sobretudo em uma região que não dispõe de hospitais gerais que recebam esses casos em seus serviços de emergência, temos pactuado com o SAMU e com outros dispositivos da RAPS e da RUE para que encaminhem à nossa equipe as pessoas que apresentem quadros de agitação psicomotora e comportamento suicida. Nestas situações, o profissional dedicado a realizar o acolhimento no dia faz a primeira abordagem, avaliando riscos e vulnerabilidades. Conforme for necessário, solicita apoio de profissionais de outras especialidades.

A prioridade é realizar o manejo verbal das situações de crise. Ainda que tenhamos um médico psiquiatra disponível para intervir nas situações de crise, ele nem sempre é acionado: a abordagem verbal é sustentada por toda a equipe, treinada em serviço para tal fim. A intervenção farmacológica só é realizada com a anuência do paciente. Entrementes, no caso das ideações suicidas, compreendemos a limitada capacidade de resolução dos psicofármacos, especialmente antidepressivos, que levam semanas para alcançar efeito terapêutico e podem incrementar o risco de risco de suicídio (Sharma, Guski, Freund \& Gøtzsche, 2016).

O encaminhamento para internação hospitalar tem se dado apenas nos casos em que a crise se mantém e não há rede de apoio presente. Este é, portanto, o critério definidor da necessidade de atendimento hospitalar. Temos observado o êxito das intervenções de base territorial, em liberdade, sempre que as famílias e o entorno social sentem-se apoiados no cuidado dos sujeitos em crise.

\section{Atividades Regulares Desenvolvidas pelo CAPS}

A agenda de atividades do CAPS tenta comtemplar diferentes necessidades dos usuários e é adequada e reavaliada constantemente. Como já mencionado, o serviço fica aberto também para que pacientes permaneçam no CAPS para convivência e interação espontânea, não necessariamente participando de alguma atividade previamente planejada. Para efeitos de apresentação, subdividimos em seis categorias as ações regularmente coordenadas pela equipe:

Reuniões multiprofissionais em grupo, em que participam os profissionais de referência e têm a função de gerenciar os Projetos Terapêuticos e acolher as demandas que os usuários apresentam espontaneamente. Ocorrem com frequência semanal, são abertas à participação voluntária e descontínua;

Grupos psicoterapêuticos, coordenados por psicólogos, com frequência semanal. Os usuários são acompanhados pelo profissional de referência da sua região de moradia;

Oficinas terapêuticas de socialização e reabilitação, coordenadas por profissionais ou estagiários de serviço social, psicologia, enfermagem e psiquiatria. A participação não é condicionada ao local de moradia;

Ações de gestão participativa e protagonismo dos usuários, com adesão voluntária;

Atendimentos individuais por especialidade, com frequência variável estabelecida entre os profissionais e os usuários e;

Grupos de intensificação de cuidados, cuja proposta é servir como espaço de cuidado transitório e flexível para pacientes em crise. 


\section{Considerações Finais}

A atuação do CAPS ora em análise tem privilegiado os atendimentos de demanda espontânea, sejam as situações de crise e urgência, as solicitações de pacientes já regularmente acompanhados ou as avaliações de pessoas que procuram o serviço pela primeira vez. Como decorrência dessa priorização e da quantidade exígua de profissionais, observamos uma sobrecarga no trabalho da equipe e uma dificuldade em manter a intensividade necessária à atenção de diversos pacientes. Assim, as consultas psiquiátricas resultam por demais espaçadas e a oferta de estratégias coletivas de cuidado e de gestão permanece um desafio a ser enfrentado por trabalhadores e usuários. Cabe destacar a dificuldade em exercer de fato o cuidado territorializado, haja vista este ser o único CAPS para atendimento ao sofrimento psíquico em geral de um município com mais de 470 mil habitantes (Instituto Brasileiro de Geografia e Estatística, 2020).

A análise dos fluxogramas descritores mostrou uma grande sistematização do processo de trabalho. Mas também denotou a importância da flexibilização das agendas e da diversificação das formas de cuidar. A inclusão das famílias nos Projetos Terapêuticos e da comunidade como um todo é ainda um caminho a ser trilhado em profundidade.

Como característica marcante, vemos a horizontalidade das decisões e das responsabilidades entre as diferentes categorias profissionais. Por outro lado, há que se reforçar a participação política, a militância de caráter antimanicomial e o controle social. Dadas as fragilidades da RAPS na região, carente de leitos de hospitalização integral em hospitais gerais e de outros dispositivos que favoreçam a desinstitucionalização de fato, o CAPS representa o principal mecanismo de efetivação da Reforma Psiquiátrica no município. Tal tarefa exige ainda muitas mudanças no processo de trabalho, passando pela qualificação da dimensão clínica (em sentido estrito e ampliado), pela crítica radical aos modelos individualistas (biomédicos, psicologistas e morais) em saúde mental e pela integração de usuários, familiares, equipe técnica e gestores no ordenamento políticas públicas de saúde no município e na transformação social - ao mesmo tempo condição de possibilidade e meta da Reforma Psiquiátrica Brasileira.

Sugere-se para trabalhos futuros pesquisas que avaliem o planejamento, a organização, a execução e a avaliação do processo de trabalho nos Centros de Atenção Psicossociais do tipo II. Essas pesquisas produzirão indicadores de avaliação que podem ser utilizados na qualificação e monitoramento do cotidiano destes serviços.

\section{Referências}

Alves A. A. M. \& Rodrigues N. F. R. (2010). Determinantes sociais e econômicos da saúde mental. Revista Portuguesa Saúde Pública. $28(2), 127-31$.

Amancio V. R (2012). Uma clínica para o CAPS: a clínica da psicose no dispositivo da Reforma Psiquiátrica a partir da direção da psicanálise. CRV.

Brasil, (2004). Ministério da Saúde. Acolhimento com Avaliação e Classificação de Risco: um paradigma ético-estético no fazer em saúde. Autor.

Brasil (2002). Ministério da Saúde. Gabinete do Ministro. Portaria n. 336, 19 de fevereiro de 2002. Estabelece CAPS I, II e III, CAPS i II e CAPS ad II. Diário Oficial de União, Brasília. Edição n. 34, Seção 1, p. 22.

Brasil (1994). Ministério da Saúde. Portaria SNAS/MS/ INAMPS n. 224, de 29 de janeiro de 1992. Estabelece diretrizes e normas para o atendimento em saúde mental. Diário Oficial de União, Brasília, 1994;

Brasil (2011). Ministério da Saúde. Portaria n. 3.088, de 23 de dezembro de 2011. Institui a Rede de Atenção Psicossocial para pessoas com sofrimento ou transtorno mental e com necessidades decorrentes do uso de crack, álcool e outras drogas, no âmbito do Sistema Único de Saúde (SUS). Diário Oficial de União, Brasília. Seção 1, p. 230-231.

Brasil (2001). Presidência da República. Lei n. 10.216, de 06 de abril de 2001. Dispõe sobre a proteção e os direitos das pessoas portadoras de transtornos mentais e redireciona o modelo assistencial em saúde mental. Diário Oficial da União, Brasília. Seção 1, p. 02.

Figueiredo M. D., Santos D. V.D . \& Weller S. (2008). Uma análise complementar do perfil dos CAPS III do município de Campinas. In: Campos R.O., Furtado J.P., Passos E. \& Benevides R., organizadores. Pesquisa avaliativa em saúde mental: desenho participativo e efeitos da narratividade. ( p.163- 188). Aderaldo \& Rothschild Editores.

Franco T. (2013). O uso do fluxograma descritor e projetos terapêuticos para análise de serviços de saúde, em apoio ao planejamento: o caso de Luz (MG). In: Franco T. Merhy E.E. Trabalho, produção do cuidado e subjetividade em saúde: textos reunidos. Hucitec.

Goodman P., Hefferline R., \& Perls F. (1997). Gestalt-terapia. Summus. 
Research, Society and Development, v. 10, n. 8, e37610817475, 2021

(CC BY 4.0) | ISSN 2525-3409 | DOI: http://dx.doi.org/10.33448/rsd-v10i8.17475

Instituto Brasileiro de Geografia e Estatística - IBGE (2020). Dado populacional do município de Florianópolis de 2019. Recuperado 27 de junho, 2021, de https://cidades.ibge.gov.br/brasil/sc/florianopolis/panorama

Kantorski L. P., Wetzel C., Olschowsky A., Jardim V. M. R., Bielemann V. L. M. \& Schneider J. F. (2009). Avaliação de quarta geração: contribuições metodológicas para avaliação de serviços de saúde mental. Interface - Comunicação, Saúde, Educação, 13(31),343-55. 10.1590/\$1414-32832009000400009

Lancetti A (2007). A clínica peripatética. Hucitec.

Merhy E. E. (1997) Em busca de ferramentas analisadoras das tecnologias em saúde: a informação e o dia a dia de um serviço, interrogando e gerindo trabalho em saúde. In: Merhy E.E. \& Onocko R., organizadores. Agir em saúde, um desafio para o público. (p. 113-150). Hucitec.

Merhy E. E. (2013). O cuidado é um acontecimento e não um ato. In: Franco T, Merhy E.E. (2013). Trabalho, produção do cuidado e subjetividade em saúde: textos reunidos. (p. 141-151). Hucitec.

Minayo, M. C. S., (2014). O desafio do conhecimento: pesquisa qualitativa em saúde. (14a ed.), Hucitec.

Müller-Granzotto M. J. \& Müller-Granzotto R. L. (2012). Clínicas Gestálticas: sentido ético, político e antropológico da teoria do Self. Summus.

Oliveira C. A., Fonseca F. C. A., do Carmo J. C., Braga K. K. L., de Lima M. F., Mamed M. C. de O., do Vale R. L. T., Magalhães R. O., Baptista S. S. G., \& Lopes G. de S. (2021). Projeto terapêutico singular (PTS): instrumento de cuidado ao sujeito em sofrimento psíquico. Revista Eletrônica Acervo Saúde, 13(2), e5709. 10.25248/reas.e5709. 2021

Oliveira G.N. (2010). O Projeto Terapêutico Singular. In: Campos GWS, Guerrero AVP. Manual de práticas da Atenção Básica: saúde ampliada e compartilhada. (cap. 12). Hucitec.

Portal, P. S. C., Santos, T. de O. C. G., Guimarães, S. do S. de V., Barreiros, M. de P., Pinto, R. B., Dias, C. H., Moraes, P. M. de O., \& Mendonça, X. M. F. D. (2021). As equipes multidisciplinares como dispositivos "técnicos de referência" em saúde mental nos caps e a gestão do cuidado: uma revisão integrativa de literatura. Research, Society and Development, 10(6), e21010615747. https://doi.org/10.33448/rsd-v10i6.15747

Prado, M. L., Morillas-Bulnes, A., \& Moran-Pena, L. (2013). Investigación cualitativa en enfermería. Metodología y didáctica. (Cap. 16, pp 193-203). Washington: Paltex.

Ribas D. L., Borenstein M. S., \& Padilha M. I. C. S. (2007). Iluminando as vivências de indivíduos em sofrimento psíquico de um CAPS em Florianópolis. Texto Contexto Enfermagem. 16(1),40-6.

Rodrigues J., Brognoli F. F., \& Spricigo J. S. (2006). Associação dos usuários de um centro de atenção psicossocial: desvelando sua significação. Texto Contexto Enfermagem.; 15(2),240-5.

Santos, A. R. (2008). Metodologia científica: a construção do conhecimento. Lamparina.

Sharma T., Guski L. S., Freund N., \& Gøtzsche P. C. (2016). Suicidality and aggression during antidepressant treatment: systematic review and meta-analyses based on clinical study reports in. $B M J ; 352: i 65.10 .1136 / \mathrm{bmj} .165$

Soares, J. P., Silva Pereira, E. R., \& Lima, J. R. (2020). Competência em saúde mental na perspectiva de profissionais de saúde que atuam em Centro de Atenção Psicossocial (CAPS). Itinerarius Reflectionis, 17(1), 01-22. 10.5216/rir.v17i1.62845

Soler C. (2012). Lacan: o inconsciente reinventado. Cia. de Freud.

Tenório F. (2007). Questões para uma atualização da agenda da Reforma Psiquiátrica. In: Couto MCV, Martinez RG, organizadores. Saúde Mental e Saúde Pública: questões para a agenda da Reforma Psiquiátrica. (pp. 13-27). NUPPSAM/IPUB/UFRJ. 